\title{
La operacionalización del desarrollo profesional de los docentes en Panamá entre las lógicas burocrática y profesional
}

\section{The Working of Professional Development of Teachers in Panama Between Bureaucratic and Professional Areas}

\author{
Mitzilla Martínez de León ${ }^{1}$ \\ Instituto Pedagógico de Namur, Bélgica \\ Namur, Bélgica \\ martinezmitzila@hotmail.com
}

Recibido: 6 agosto 2012 Aceptado: 26 febrero $201 \quad$ Corregido: 31 abril 2013

\begin{abstract}
Resumen: Por la operacionalización ${ }^{\mathrm{I}}$ del desarrollo profesional del personal docente, el sistema educativo panameño establece un funcionamiento que articula las lógicas ${ }^{\mathrm{II}}$ burocrática y profesional. En este marco, el objetivo de este estudio es contribuir a la comprensión de la cohabitación de las lógicas burocrática y profesional en las acciones que concretizan los actores educativos de los diferentes niveles institucionales (central, regional y local), con la finalidad de operacionalizar el desarrollo profesional del personal docente. En el estudio se utilizó el enfoque cualitativo. Así, se realizaron entrevistas a profundidad, que permitieron tomar en consideración las representaciones (opiniones, ideas) de diferentes actores educativos acerca de la dinámica de desarrollo profesional. A través de la técnica de análisis de contenido, utilizada para tratar las entrevistas, se revela que la presencia de las dos lógicas (burocrática y profesional) genera una tensión que es considerada, más bien, positiva. En efecto, se demuestra que esta tensión conduce a los diferentes actores educativos de los niveles central, regional y local a hacer cohabitar las lógicas, permitiendo así la articulación de sus principios: centralización-control (Lógica burocrática) y descentralizaciónautonomía (Lógica profesional). Sin embargo, la cohabitación de las lógicas es diferente, según su funcionalidad en los diversos niveles institucionales (central, regional, local). Asimismo, se destaca que la "cohabitación funcional" se conjuga con una "comunicación institucional" según el rol (controlador-coordinador, intermediario, operador) que los actores educativos ejercen en la institución, lo cual favorece la operacionalización del desarrollo profesional. En suma, la cohabitación de las lógicas organizacionales permite que la institución educativa mantenga la finalidad de su misión de desarrollo profesional dentro del marco legal y a la vez otorgue la posibilidad, a los actores educativos y a los colaboradores exteriores, de actuar conforme a un margen de autonomía.
\end{abstract}

Palabras claves: Desarrollo profesional, lógicas burocrática y profesional, centralización-control, descentralización-autonomía.

\footnotetext{
Magister-Estudios complementarios en ciencias de la educación (DEC). Igualmente, es Magister-Estudios Especializados en Ciencias de la Educación (DES). Ambas Maestrías fueron realizadas en la Universidad Católica de Lovaina la Nueva (UCL) en Bélgica. En ésta universidad y en las Facultades Universitarias Nuestra Señora de la Paz (FUNDP) en Bélgica, está por culminar, actualmente, su programa de doctorado en educación, pre-Bolonia. Realizó su Licenciatura y su Profesorado en educación (diversificada) en la Universidad de Panamá (República de Panamá). Asimismo, obtuvo su diploma de Maestra de enseñanza primaria en la escuela Normal Juan D. Arosemena (Santiago-Panamá). Ejerce, recientemente, como formadora de formadores en el Instituto Pedagógico de Namur (Bélgica). Se ha desempeñado como investigadora en educación en el Departamento de Educación Tecnología (FUNDP-Namur-Bélgica) y como acompañante de proyectos educativos y de formación continua de los docentes en el Gran Ducado de Luxemburgo. Ha ejercido como asistente del curso de profesorado (diversificado) en las Facultades Nuestra Señora de la Paz en Namur - Bélgica. Ha sido consejera pedagógica para los docentes de secundaria (SeDESS) Namur- Bélgica. Trabajó como docente en diferentes centros escolares en la República de Panamá, de donde es originaria.
} 


\begin{abstract}
The Panamanian educational system implements both a bureaucratic and a professional logic when teachers' professional development takes place. In this context, the aim is to contribute to the understanding of bureaucratic and professional areas evidenced in the actions of educational members at the different institutional levels (central, regional, local) in order to work on teachers' professional development. The study used a qualitative approach; thus, in-depth interviews were done, allowing the consideration of representations (opinions, ideas) of different educational actors about the dynamics of professional development. Content analysis technique, used to treat interviews, showed that the presence of the two logics (bureaucratic and professional) generates a positive tension. Indeed, it is proved that this tension guides educational actors in central, regional and local levels to make the logics co-exist thus allowing the articulation of its principles: centralizationcontrol (bureaucratic logic) and decentralization-autonomy (professional logic). However, the coexistence of these areas differs according to their functionality in the different institutional levels (central, regional, local). Additionally, it is stressed that "functional co-existence" together with an "institutional communication" fosters professional development according to the role (controllingcoordinating, intermediary, operator) that educational actors have in the institution. Likewise, the organizational logic's co-existence allows the educational institution to maintain the purpose of professional development, within the legal framework and, at the same time, gives the chance to educational actors and external collaborators to act with some autonomy.
\end{abstract}

Keywords: Professional development, bureaucratic and professional, area, centralization-control, decentralization - autonomy.

\title{
Introducción
}

El Estado panameño establece la reforma de modernización de las distintas instituciones gubernamentales desde 1991. Dentro de esta perspectiva, una reforma educativa denominada "Estrategia decenal de modernización escolar", sostenida por la ley n. ${ }^{\circ} 34$ de julio de 1995, es puesta en práctica a partir de 1997. Esta reforma educativa implica, lógicamente, cambios en la gestión y la organización administrativa y académica del sistema educativo, con el fin de minimizar la inequidad del servicio educativo y mejorar la calidad de la educación.

Esta modernización de la educación propone una visión a largo plazo (10 años), que se prolongó a 15 años, con la finalidad de garantizar la continuidad de las políticas y de los proyectos educativos, los cuales favorecen una revisión integral de los principios, de las estructuras y del funcionamiento del sistema educativo. Esta visión se concretará, a través de la construcción de un modelo de educación democrático y de calidad ${ }^{\text {III }}$. Con este propósito, se propone la implantación de un funcionamiento descentralizado y autónomo, en todos los niveles del sistema educativo. En este contexto de cambio, una de las prioridades de la modernización de la Educación es favorecer el desarrollo profesional del personal docente, de una manera continua e integral; ya que estos actores son considerados como una "piedra angular" para obtener los resultados esperados.

Así, considerando que el cambio institucional y, por ende, el desarrollo profesional, están inscritos dentro de un marco legal, que a la vez sostiene una gestión descentralizada; se puede concebir, en primera instancia, que el funcionamiento de la institución educativa es burocrático-profesional (Mintzberg, 1982, 1986; 1996, Hatch, 2001). Dada esta consideración, a través de este estudio, el interés primordial es comprender, cómo el funcionamiento 
burocrático o profesional de la institución educativa en los diferentes niveles (central, regional $y$ local) es favorable al desarrollo profesional de los docentes.

La complementariedad entre las lógicas burocrática y profesional ha sido demostrada en estudios anteriores (Mintzberg, 1982, 1986; Bonami, 1996). Sin embargo, la particularidad de este estudio consiste en que hemos tratado las lógicas organizacionales (burocráticas y profesional) combinándolas con las variables de la operacionalización de la dinámica del desarrollo profesional y el funcionamiento de los tres niveles institucionales (central, regional, local) del sistema educativo panameño. Por ello, para comprender el vínculo entre lo organizacional ${ }^{\mathrm{IV}}$, lo funcional y lo profesional, se hizo referencia a la literatura relativa al análisis socio-organizacional y al desarrollo profesional. De igual manera, en el estudio se aplicó el método cualitativo, el cual se caracterizó por un carácter exploratorio, una visión comprensiva y una óptica descriptiva e interpretativa. Además, los procedimientos cualitativos, puestos en práctica, se controlaron a través de diferentes criterios científicos, tales como: la validación, fiabilidad, la triangulación y la saturación.

En la fase empírica, se contactaron actores educativos de los diferentes niveles institucionales (central, regional y local), a los cuales se les realizó una entrevista a profundidad con la finalidad de obtener sus representaciones acerca de la dinámica de desarrollo profesional. De esta manera, se obtuvieron resultados en relación con las acciones ejecutadas por los actores educativos, con el propósito de operacionalizar el desarrollo profesional de los docentes, en un marco normativo, conjugándolo simultáneamente con un margen de autonomía.

\section{Concepciones teóricas del desarrollo profesional}

La expresión "desarrollo profesional" se utilizaba poco en los años sesenta. Esta comienza a ser más frecuente en los años noventa, puesto que el desarrollo profesional se convierte en un tema de estudio específico en el ámbito de la educación, tal como es resaltado por Miller (1990). Así, Lieberman y Miller (1990, p.1045) consideran que "el desarrollo profesional es definido por todos los conocimientos, capacidades y condiciones necesarios para el perfeccionamiento de los docentes en su trabajo".

Los aspectos formales e informales son tomados en cuenta en el desarrollo profesional, según Fullan y Stiegelbauer (1994). En efecto, estos actores consideran que el desarrollo profesional puede definirse como "la suma de los aprendizajes efectuados de manera formal o informal, durante la carrera de un individuo, desde su inicio hasta su jubilación" (Fullan y Stiegelbauer, 1994, p. 326, citado por Boucher y L’Hostie, 1997, p. 88). De manera general, estos actores destacan que el impacto del desarrollo profesional está vinculado, íntimamente, a la motivación del individuo y a la oportunidad de aprender. En este sentido, Jean-Marie Barbier y sus colegas (1996, p. 119-120), Barbier, Chaix y Demailly (1994, p.7), conciben el desarrollo profesional en un contexto amplio, que cubre todas las transformaciones individuales y colectivas.

Para J. Donnay y E. Charlier (2000, p.5), el desarrollo profesional "es un proceso de aprendizaje dinámico y continuo que permite obtener competencias y actitudes propicias al aprendizaje, de otras 
competencias y actitudes». Sin embargo, Holborn y Wideen (1993) piensan, de manera general, que el desarrollo profesional considerado como un proceso educativo exige un compromiso activo y atento del individuo.

Así, más recientemente, J. Donnay y E. Charlier (2006, p.13) definen el desarrollo profesional como “...un proceso dinámico y recurrente, intencional o no, por el cual, en las interacciones con la alteridad, y en las condiciones que lo permiten, una persona desarrolla sus competencias y sus actitudes inscritas en valores educativos y una ética profesional...”. Por lo tanto, estos actores concluyen que este proceso de aprendizaje no puede ser sino dinámico y continuo.

Este proceso se desarrolla en la autonomía, sobre todo, porque cada uno es protagonista y el principal responsable de su desarrollo profesional (Charlier y Donnay, 2006). Estos mismos autores piensan (En Abou, A. y Guiletti, M. - J., 2000, p. 46) que “...considerar el aprendizaje del profesional, en una perspectiva de desarrollo, es también darle a los individuos la responsabilidad de la calidad y de la evolución de su aprendizaje”. No obstante, Charlier y Donnay (2006) resaltan que para que los individuos ejerzan su responsabilidad es necesario un contexto organizacional, que puede ser más o menos favorable y que les dé oportunidades para administrar su aprendizaje profesional.

En esta línea, actores como Perrenoud, P. (1994) y Vonk, J.C. (1988) afirman que el desarrollo profesional es un proceso que podría implicar una primera etapa, a partir de la formación inicial de los docentes, de tal forma que estos se apropien de la importancia de la dinámica, de la adquisición continua de conocimientos, de actitudes, de competencias, entre otros. Los docentes podrán, entonces, seguir este proceso, de manera formal o informal, a lo largo de su carrera profesional teniendo a la vez el apoyo del sistema educativo.

A través de estas distintas concepciones emitidas por diferentes actores, podríamos considerar que el desarrollo profesional es concebido como un proceso dinámico y permanente. Sin embargo, existen sistemas educativos y docentes que mantienen, probablemente, la práctica de un desarrollo profesional tradicional y estático. Esto podría estar en contradicción con las expectativas actuales de los contextos educativos y sociales.

\section{Las lógicas organizacionales en el contexto educativo}

Desde hace algunas décadas, actores como Bidwell (1956), Perrou (1970) y Spencer (1976) (citados por Mintzberg, 1982) dieron a conocer que, generalmente, la burocracia profesional se define en los sistemas escolares, la policía y el medio hospitalario.

En este sentido, de acuerdo a la teoría de Mintzberg (1982), la escuela es una burocracia profesional cuya estructura se basa en la "estandarización ${ }^{v}$ de las competencias" de los actores. Según este autor, las competencias se actualizan a través de la formación y la socialización de sus miembros. Estos dos parámetros son necesarios en el apoyo del desarrollo profesional de los docentes. Asimismo, Brunet y Brunet (2001) consideran que la escuela recluta profesionales, precedentemente, formados así que socializados, y les da la oportunidad de controlar su propio trabajo. Además, estos autores piensan que la existencia de una doble lógica es el 
origen de contradicciones organizacionales importantes. Por el contrario, M. Bonami (1996, p. 186) afirma que "los centros escolares son apoyados por dos lógicas organizacionales, a la vez contradictorias y complementarias. Estas lógicas son la burocrática y la profesional". A partir de esta afirmación, podríamos considerar que, en general, las escuelas no adoptan, exclusivamente, una lógica organizacional. Además, podemos plantear la hipótesis de que la gestión de estas dos lógicas, por parte de los actores, podría contribuir al equilibrio de las relaciones entre estos, a la adaptación de las evoluciones y al funcionamiento de la escuela.

\section{Lógica burocrática}

Max Weber (citado por Chavy, J. y Dampierre, E., 1971) y H. Mintzberg (1990) estudiaron la lógica burocrática en el marco de la empresa. Más recientemente, M. Bonami (1996) la sitúa en el contexto del centro educativo. Según este autor, la lógica burocrática se inscribe en una organización estructurada, con base en numerosas reglamentaciones, bastante estrictas. En efecto, el carácter burocrático se manifiesta, principalmente, a través de un repertorio de reglamentaciones, que estructuran y organizan la vida de los estudiantes y de los docentes, en relación a su estatuto, su rol, a los programas de estudios, al tiempo escolar y a la utilización de los recursos financieros (Gustin, 2002).

En este sentido, Gather-Thurler (2000) piensa que en el contexto de la escuela, la lógica burocrática es, considerablemente, interiorizada por los actores. Esta lógica reduce, enormemente, las necesidades de coordinación entre docentes y no estimula, en ningún caso, el desarrollo de las competencias relacionales, de gestión, de reflexión, etc. De esta manera, se podría suponer que los docentes no tienen la oportunidad o no consideran la necesidad de reflexionar sobre su práctica.

Esta autora confirma que existen límites de la lógica burocrática. En efecto, por el hecho de la "estandarización", en la mayoría de los casos esta lógica no toma en cuenta las necesidades individuales. Además, el funcionamiento estandarizado evita la puesta en práctica de una reflexión para solucionar los problemas.

Sin embargo, la lógica burocrática cuenta con parámetros interesantes, como lo manifiesta Gather-Thurler (2000). De acuerdo con la autora, esta lógica racionaliza el trabajo con base en los procedimientos estandarizados, decididos por las autoridades o fijados por los especialistas. Así, la burocracia permite a los docentes de concentrarse sobre el trabajo pedagógico en el salón de clase, sin tener que preocuparse de los problemas administrativos.

No obstante, Bonami (1996) afirma que la escuela funciona también con una lógica profesional, por la cual, de una u otra manera, un equilibrio se establece en los procedimientos basados en la lógica burocrática.

\section{Lógica profesional}

Autores como Bonami (1996) y Gustin (2002) certifican, a través de sus estudios, que de acuerdo a la lógica profesional los centros escolares son percibidos como organizaciones 
que cuentan con un personal capaz o considerado como especialistas, que pueden realizar su trabajo de manera autónoma. Esta lógica concede a los docentes la posibilidad de tomar decisiones en su terreno de acción. El carácter profesional se puede notar en los numerosos espacios de libertad otorgados a los docentes para concebir, aplicar y evaluar los aprendizajes.

Tal que la lógica burocrática, la lógica profesional revela parámetros interesantes. Gather-Thurler (2000) considera que la principal contribución de la lógica profesional consiste en combatir la ilusión de una racionalidad, basada en la organización centralizada del trabajo. Esta lógica introduce la exigencia de la autonomía y la responsabilidad, como condición de la eficacia, en el ejercicio de la profesión.

Sin embargo, si el trabajo de los actores educativos solamente es basado en los parámetros de la lógica profesional, esto podría conducir a algunos actores a actuar aisladamente, a crear su micro-atmósfera, a descuidar el funcionamiento y los objetivos colectivos. Por tal razón, pensamos que la lógica burocrática contribuye a establecer un equilibrio en la manera de funcionar del personal docente.

En suma, por un lado, la lógica burocrática define e impone procedimientos de trabajo considerados óptimos para concretizar los objetivos fijados. Por otro lado, la lógica profesional limita el trabajo prescrito, no por respeto incondicional de la autonomía de cada uno, sino considerando que las buenas soluciones surgen, durante las acciones diarias de trabajo, de acuerdo a la complejidad de las situaciones y no solamente a través de procedimientos estandarizados (Gather-Thurler, 2000).

Además, podríamos suponer que la lógica burocrática estimula el respeto de la norma y la lógica profesional permite el uso del margen de libertad. Las dos lógicas estructuran el universo del establecimiento escolar y de sus actores.

\section{Metodología}

El estudio se inscribe en un enfoque cualitativo, de carácter exploratorio, con una visión comprensiva, descriptiva e interpretativa. El enfoque cualitativo ha sido apropiado para el estudio puesto que a través de este se busca comprender la operacionalización de la dinámica de desarrollo profesional a partir, principalmente, de las representaciones (ideas, opiniones) de los actores educativos.

A través del enfoque cualitativo, se evitó que el estudio se desarrollara de manera lineal. En efecto, durante el proceso investigativo, se pudo manejar las situaciones imprevistas, cambiar preguntas, conceptos y confrontar ideas que se tuvieron al principio de la investigación con la información que arrojaba el trabajo de campo, teniendo en cuenta el objetivo de estudio.

La primera tarea fue de investigar sobre la literatura de referencia, con el objeto de identificar conceptos y teorías pertinentes para el estudio. Posteriormente, la fase del trabajo empírico fue enmarcada por una serie de procedimientos que requirieron, en primera instancia, el contacto con actores educativos y la familiarización con el contexto de estudio. Estos procedimientos se realizaron sin haber determinado definitivamente la técnica de recolección de información ni la muestra de referencia. 
Después de los contactos preliminares, se eligió la entrevista como instrumento para la recopilación de la información. Además, se optó por el estudio de documentos, con el proósito de completar ciertas informaciones. En cuanto a la muestra, se decidió trabajar con actores de los diferentes niveles institucionales (central, regional y local) que conforman el sistema educativo panameño.

\section{Muestra del estudio}

Se trabajó con una muestra razonada de estilo bola de nieve. Este estilo de muestra permitió contactar progresivamente los actores, partiendo de los contactos facilitados por otros actores. De manera a triangular las informaciones obtenidas a través de las entrevistas, la muestra del estudio se conformó con actores de los diferentes niveles: central, regional y local. Se estableció como criterio para la muestra de actores que los mismos estuvieran en relación con la operacionalización de la dinámica del desarrollo profesional del personal docente. Por otra parte, se integró en la muestra a los colaboradores exteriores, quienes se asociaron al nivel central, y los sindicatos, que se adjuntaron al nivel regional.

Para definir la muestra de documentos, se estableció como criterio seleccionar aquellos que hicieran referencia, de manera oficial, al funcionamiento del sistema educativo panameño y a la dinámica de desarrollo profesional. Hay que destacar que algunos de los documentos fueron sugeridos por actores entrevistados.

A continuación presentamos las Tablas 1, 2 y 3A, 3B) que reagrupan los actores que conformaron cada una de la muestra por nivel, así como los criterios de selección. Igualmente, presentamos el cuadro (n. $\left.{ }^{\circ} 4\right)$ concerniente a la muestra de documentos.

El la Tabla 1 presenta la muestra de actores de nivel central, la cual se constituyó con actores de la jerarquía central del Ministerio de Educación y los colaboradores exteriores gubernamentales y no gubernamentales.

Tabla 1

Muestra de actores de nivel central y criterios de selección

Muestra

Criterios de selección

\begin{tabular}{lll}
\hline A nivel central del Ministerio de Educación: & $\begin{array}{l}\text { Actores que hayan participado en la elaboración del } \\
\text { contenido de la nueva dinámica de desarrollo profe- } \\
\text { sional del personal docente }\end{array}$ \\
$\begin{array}{ll}\text { Planificador educativo general } \\
\text { Director nacional de formación y actual- }\end{array}$ & $\begin{array}{l}\text { Actores que tienen relación con las acciones y } \\
\text { ización profesional los procedimientos puestos en práctica por la }\end{array}$ \\
$\begin{array}{l}\text { Técnico-docente de la dirección nacional de } \\
\text { formación et actualización profesional }\end{array}$ & $\begin{array}{l}\text { operacionalización de la nueva dinámica de } \\
\text { desarrollo profesional del personal docente }\end{array}$ \\
\hline
\end{tabular}

$>$ Colaboradores exteriores:

- Representante de la fundación Gabriel Lewis Galindo

- Colaboradores exteriores que intervienen directamente en la dinámica de desarrollo profesional del

- Representante de la secretaría nacional de personal docente ciencias, tecnología e innovación (SENACYT) 
Es importante señalar que para la muestra de los niveles regional y local, se trabajó con dos provincias de las nueve que hacen parte de la geografía panameña. Se escogieron las provincias de Coclé y de Panamá. Estas provincias constituyen de regiones que se consideraron pertinentes e interesantes para nuestro estudio puesto que son de contextos geográficos, culturales, económicos, sociales y demográficos diferentes. La provincia de Panamá incluye la capital del país. La provincia de Coclé hace parte del resto de la provincia del país.

La Tabla 2 presenta la muestra de actores de nivel regional, la cual se formó con actores de la jerarquía regional del Ministerio de Educación y representantes de los sindicatos de docentes.

Tabla 2

Muestra de actores de nivel regional y criterios de selección

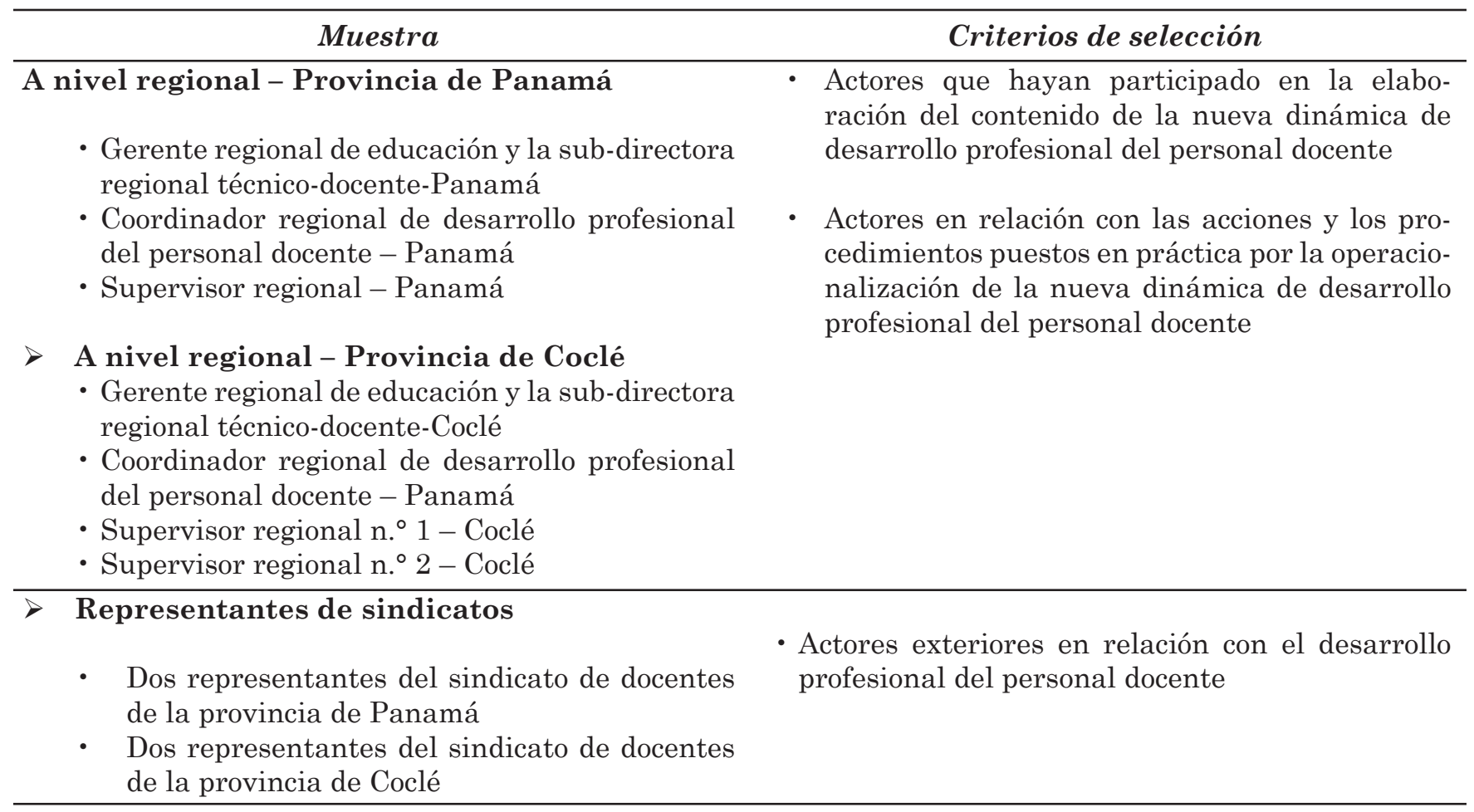

Las tablas 3-A y 3-B presentan la muestra de actores de nivel local, la cual está integrada por directores y docentes coordinadores de grado de centros educativos de educación primaria. Para la muestra del nivel local, se trabajó con dos centros educativos en cada provincia. 
Tabla 3-A

Muestra de actores de nivel local (directores y subdirectores de centros educativos) y criterios de selección

\begin{tabular}{|c|c|}
\hline Muestra & Criterios de selección \\
\hline \multicolumn{2}{|l|}{ Directores de centros educativos ${ }^{1}$ : } \\
\hline $\begin{array}{l}\text { Directores de centros educativos de la } \\
\text { provincia de Panamá } \\
\text { Director y subdirector de la escuela } \\
\text { República de Chile } \\
\text { Director y subdirector de la escuela } \\
\text { República de Venezuela }\end{array}$ & $\begin{array}{l}\text { - Directores y subdirectores de escuelas que ponen } \\
\text { en práctica acciones que favorecen el desarrollo } \\
\text { profesional del personal docente } \\
\text { - Directores que hacen parte de las escuelas que } \\
\text { asumen una posición crítica del proceso de desar- } \\
\text { rollo profesional del personal docente }\end{array}$ \\
\hline $\begin{array}{l}\text { Directores de centros educativos de la } \\
\text { provincia de Coclé: } \\
\text { - Director y subdirector de la escuela Doctor } \\
\text { Manuel Patiño } \\
\text { - Director y subdirector de la escuela } \\
\text { República Dominicana }\end{array}$ & $\begin{array}{l}\text { Directores que pertenecen a escuelas que tienen } \\
\text { un tiempo de existencia y son reconocidas por dar } \\
\text { importancia a la dinámica de desarrollo profesion- } \\
\text { al del personal docente }\end{array}$ \\
\hline
\end{tabular}

1 Tres de las escuelas que se seleccionaron para el estudio poseen nombre de países que corresponde a países de América Latina.

Tabla 3-B

Muestra de actores de nivel local (docentes coordinadores de grado) y criterios de selección

\section{Muestra}

\section{$\checkmark$ Coordinadores de grado:}

\section{Provincia de Panamá:}

- Seis docentes coordinadores de grado de la

escuela República de Chile

- Seis docentes coordinadores de grado de la escuela República de Venezuela

\section{Provincia de Coclé:}

- Seis docentes coordinadores de grado de la escuela Doctor Manuel Patiño

- Seis docentes coordinadores de grado de la escuela República Dominicana

\section{Criterios de selección}

- Docentes que tienen conocimiento del funcionamiento de la escuela

Docentes que conocen y participan en las acciones que son puestas en práctica en la escuela, para sostener el desarrollo profesional del personal docente 
La tabla 4 reagrupa la muestra de documentos.

Tabla 4

Muestra de documentos

\section{Muestra}

Ley n. ${ }^{\circ} 47$ de 1946 orgánica de la educación con las modificaciones introducidas a la ley n. ${ }^{\circ} 34$ del 6 julio de 1995

Estrategia decenal de modernización de la educación panameña

$>$ Decreto ejecutivo n. ${ }^{\circ} 202$ de 10 de octubre de 1988. Creación de la dirección de Perfeccionamiento del docente y la unidad técnico docente

$>$ Resuelto n. ${ }^{\circ} 425$ del 30 de marzo de1989 que reglamenta el Decreto n. ${ }^{\circ} 2002$. Funcionamiento de las actividades de formación continua

$>$ Decreto ejecutivo n. ${ }^{\circ} 576$ del 21 de julio 2004. Creación del Sistema Nacional de Formación y de desarrollo profesional integrado

$>$ Proyecto de desarrollo educativo-Ministerio de la educación. Eje de desarrollo profesional

$>$ Decreto ejecutivo n..$^{\circ} 100$ del 10 febrero de 1957, establece las funciones del personal de educación

$>$ Decreto ejecutivo n. ${ }^{\circ} 538$ del 29 septiembre de 1951. Ética profesional del personal de educación

$>$ Documento de Síntesis del Ministerio de Educación de 2002. Personal docente: perfil, formación y desarrollo

$>$ Informe del desarrollo humano

$>$ Informe del Ministerio de Educación de 1990 a 2005

$>$ Informe del Ministerio de Educación de 1990 a 2005 y de la oficina del PNUD (Programa de las Naciones Unidas) "Diálogo por la transformación integral del sistema educativo"

$>$ Informe del Foro Nacional de la Educación panameña: por la calidad y la pertinencia y la equidad, 2005

> Documento informativo del Ministerio de Educación de Panamá, 2005. Líderes y proyecto educativo en las escuelas

$>$ Documento informativo del Ministerio de Educación de Panamá, 2006. Hacia una escuela nueva del siglo XXI

\section{Técnicas de recolección de la información}

Se decidió trabajar con la entrevista cualitativa a "profundidad" para recolectar la información. Para la entrevista se construyó una guía para cada nivel institucional. Las guías se constituyeron con preguntas a las cuales se denominaron "operacionales", puesto que son las que orientaron principalmente la entrevista. Asimismo, se elaboraron preguntas denominadas de "recuadro", que se utilizaron para ayudar a los entrevistados a explicar ciertos razonamientos o acciones y para, en cierta forma, centrar las informaciones en función del objetivo del estudio. 
Las guías fueron validadas a través de un proceso de verificación por parte de actores educativos. Sin embargo, al momento de la entrevistas, las guías no se siguieron de manera rígida, puesto que se estuvo abierto a la posibilidad del surgimiento de nuevos temas vinculados con el interés del estudio, pero que no fueron previstos.

En anexo se expone la matriz que contiene las guías de las entrevistas, por cada nivel institucional. Las guías presentan por cada grupo de actores las preguntas "operacionales" y las de "recuadro", así que los conceptos de referencia (literatura).

\section{Tratamiento e interpretación de la información}

Posteriormente del trabajo de campo, se inició el tratamiento de los datos contenidos en las entrevistas y en los documentos, utilizando el análisis de contenido (Paille, P. y Mucchielli, A. , 2003). Esta técnica favoreció el descubrimiento del sentido implícito en las informaciones, así como la integración de nuevos elementos que surgieron del análisis.

Respondiendo al análisis de contenido, se aplicaron las etapas de preanálisis y análisis de datos. En la etapa de preanálisis se siguieron los procedimientos siguientes:

- Se elaboró el corpus a analizar, el cual se compuso con la información obtenida a través de la entrevistas y de los documentos seleccionados.

- Se transcribieron las entrevistas, por lo cual se realizaron, previamente, repetidas audiciones, con la finalidad de conservar la integridad de las informaciones. La verificación y la confirmación del contenido de las transcripciones fueron realizadas por los actores entrevistados. Se asignó un código a cada entrevista, igualmente que a los documentos.

- Puesto que el corpus se formó con una cantidad considerable de contenido, se decidió reducirlo, con el objeto de manejarlo de manera más eficaz durante la etapa del análisis. Para la reducción se tomó en cuenta la pertinencia del contenido a retener, en función del objetivo del estudio.

En lo que concierne a la etapa de análisis, se realizaron los procedimientos siguientes:

- Se realizó la segmentación del contenido del corpus, para poder presentarlo de manera legible. Para tal finalidad, se identificaron unidades de muestreo, a las cuales se les agregaron la codificación asignada a las entrevistas y a los documentos.

- Se integraron las unidades de muestreo en categorías transitorias, relacionadas con los diferentes niveles institucionales (central, regional y local). En el proceso de categorización, se tomó en consideración el razonamiento deductivo e inductivo. A medida que se avanzó en este proceso, ciertas categorías se confirmaron, algunas cambiaron o fueron eliminadas o integradas con otras, asimismo surgieron nuevas categorías. A las categorías se adjuntaron componentes (Huberman, 1991) puesto que los datos tratados no correspondían a la características de subcategorías. 
- Posteriormente, se realizó una nueva estructuración, con la finalidad de alimentar la categorización. En esta ocasión, las unidades de muestreo se sintetizaron, transformándolas así en unidades de registro. Estas unidades requirieron un proceso de reflexión, para evitar cambiar el sentido de la información.

- Se aplicó el proceso de descontextualización para identificar las categorías que no tenían un carácter realmente funcional, lo cual permitió redefinirlas, asociarlas, etc. En este proceso, solicitamos la participación de personas que conocían o no el contexto educativo panameño para así validar el cuadro de análisis integrado por las categorías (Huberman y Miles, 1991; Bardin, 2001). Con base en los resultados de la descontextualización se realizó una nueva restructuración del cuadro de análisis integrado por las categorías. De esta manera, se obtuvo un cuadro definitivo para tratar e interpretar los datos.

En la fase de tratamiento e interpretación de los datos, se realizaron lecturas cruzadas de las distintas categorías definidas en los diferentes niveles institucionales, tomando en cuenta el objetivo del estudio. De esta manera, se destacaron, particularmente, datos concernientes a los ejes de la operacionalización del desarrollo profesional del personal docente y funcionamiento burocrático y profesional. A través de estos ejes, se identificaron los conceptos de centralización, descentralización, control y autonomía. A partir de estos conceptos, se interpretaron los elementos específicos (citados por un solo actor) y elementos compartidos (citados por varios actores). En la fase de interpretación se tomó en cuenta la teoría de referencia y se destacó las nuevas constataciones. Se discutieron los resultados, lo cual permitió elaborar un modelo comprensivo y a partir del mismo emitir las conclusiones. En los puntos siguientes presentamos los principales resultados obtenidos a través de este estudio.

\section{La cohabitación entre lógicas organizacionales}

Actores de los niveles central, regional y local, así como los documentos legales confirman que el Estado, a través de su poder legal, confiere a la institución educativa el poder de gestión. En efecto, esta institución tiene la responsabilidad directa de organizar y dirigir el servicio de la educación. Por tal finalidad, la institución establece un funcionamiento articulado, con base en la complementariedad de las lógicas organizacionales (Mintzberg, 1986; Bonami, 1996). Así, la institución educativa ejerce su responsabilidad, poniendo en práctica un funcionamiento que se podría describir como centralizado (Mintzberg, 1982, 1986; Hatch, 2001), respondiendo a la lógica burocrática y a la vez de un carácter descentralizado, el cual responde a la lógica profesional (Mintzberg, 1982, 1986; Hatch, 2001). Dada esta constatación, podríamos considerar que el funcionamiento de la institución educativa panameña se caracteriza como burocrático-profesional.

Sin embargo, la presencia simultánea de las lógicas burocrática y profesional genera una tensión. Esta se considera, más bien, positiva, ya que se transforma en una "fuerza de dinamismo" en la concretización de estas dos lógicas. En efecto, esta tensión conduce a los 
actores a enmarcar sus acciones, en acuerdo con la cohabitación de estas dos lógicas. De esta forma, la cohabitación implica la conciliación de las dos concepciones opuestas y favorece la instauración de los procedimientos que permiten la articulación de los principios de las lógicas burocrática y profesional. Estos principios son: centralización-descentralización y control-autonomía.

No obstante, la cohabitación es concretizada "más fácilmente" por los actores que están en una dinámica de innovación, de creación, de aprendizaje activo, de compartir, que conocen sus derechos y sus deberes, etc., ya que ellos podrían apropiarse de los principios de las lógicas, en todas las situaciones y momentos, de manera individual o colectiva.

Por otra parte, cabe destacar que una de las particularidades del sistema educativo panameño consiste en que la descentralización está prescrita. Esta se convierte en un apoyo legal para los actores educativos, con el fin de operacionalizar la dinámica de desarrollo profesional de los docentes. En realidad, la prescripción (burocracia) de la descentralización (profesional) refleja la cohabitación de la lógica burocrática y de la lógica profesional. Sin embargo, si tomamos en cuenta la percepción que tienen algunos actores acerca de la apropiación de la descentralización, encontramos que hay varias opiniones que corren el riesgo de convertirse en "dificultades". En efecto, un obstáculo principal, que está presente en todos los niveles (central, regional y local), es "el hábito" de algunos actores de ejercer dentro de un marco legal, dado que se sienten seguros, no deben reflexionar para la concretización de las normas legales, funcionan de manera sistemática, etc. Pero, por el contrario, otros actores corren el riesgo de irse al extremo, olvidando casi sus deberes y las normas legales, puesto que tienen necesidad de innovar según sus propias convicciones, porque requieren de un margen más amplio de libertad, etc. Así, en el centro educativo, estas distintas posiciones pueden causar relaciones tendidas entre los actores de terreno, puesto que algunos docentes funcionan, de manera exclusiva, de acuerdo a una lógica burocrática y otros según la lógica profesional, lo que puede conducir a interpretar los objetivos y las normas colectivas de acuerdo particularmente al modo de funcionamiento utilizado. En este tipo de situación, la cohabitación de las lógicas organizacionales podría contribuir a establecer un equilibrio en el funcionamiento del personal docente.

En este contexto, todo indica que un hecho concreto, que responde a la descentralización de la gestión del desarrollo profesional, es la creación y la institucionalización (Decreto 576) del SINDEPRO (Sistema Nacional de Desarrollo Profesional). Esta disposición legal (burocrática) es propicia a la operacionalización del desarrollo profesional, inscrita en un marco legal de descentralización (profesional), lo que en primera instancia parece paradójico.

En efecto, el SINDEPRO apoya la reestructuración de la dinámica del desarrollo profesional. Este sistema favorece el acercamiento con los actores del terreno con el fin de tener en cuenta sus verdaderas necesidades de desarrollo profesional. Por otro lado, para hacer efectiva su misión, el SINDEPRO concibe, estratégicamente, un subsistema y crea el puesto de coordinador regional del desarrollo profesional en cada una de las trece regiones educativas que componen el sistema educativo panameño. Destacamos que estos dos componentes del SINDEPRO funcionan en colaboración, en el nivel regional para el nivel local, a través de procedimientos descentralizados y autorizados legalmente por el nivel central. 
Podemos mencionar dos beneficios importantes de la creación de estos dos componentes a nivel regional. El primero consiste en la contribución para disminuir el sentimiento de insatisfacción de los docentes de las provincias, causado por la inequidad en la accesibilidad de las ocasiones de desarrollo profesional. En efecto, esta inequidad es producida por ciertos procedimientos centralizados y de control (administrativo y organizacional). El segundo es el apoyo eficaz para la operacionalización del desarrollo profesional, que ellos pueden brindar a nivel local. Sobre todo, en los centros educativos en los cuales no se practica aún la "gestión compartida". No obstante, pensamos que a través de los componentes del SINDEPRO, a nivel regional, las particularidades de los distintos contextos de los centros educativos pueden ser mejor tratadas.

Sin embargo, es necesario dar "tiempo" para que los actores de terreno se apropien de la visión de descentralización del SINDEPRO, sobre todo, que la implementación de este sistema implica un cambio de actitudes profesionales y en aspecto relacional.

El SINDEPRO tiene el poder persuasivo ${ }^{\mathrm{VI}}$ (Galbraith, 1985) de autorizar las acciones de desarrollo profesional, incluyendo aquellas que los colaboradores exteriores (gubernamentales y no gubernamentales) y los sindicatos proponen. Estos actores adoptan la cohabitación de las lógicas, puesto que deben tomar en cuenta el marco legal de la institución educativa, pero a la vez tienen un margen de autonomía.

De este modo, se pudo constatar que el colaborador exterior gubernamental, que participó en el estudio, practica una gestión del desarrollo profesional, similar a la del Ministerio de la Educación, por su estatuto de institución gubernamental. En efecto, este colaborador basa sus acciones de desarrollo, más que todo, en el aspecto profesional del docente. Por el contrario, el colaborador exterior no gubernamental practica la diversificación en sus acciones de desarrollo profesional. Esta diversificación toma en cuenta el aspecto personal del docente, de manera considerable, con la finalidad de (re)activar el aspecto profesional. Los resultados de esta diversificación son valorizados por todos los actores educativos y en particular por los docentes, puesto que llenan sus expectativas en el ámbito personal y profesional.

Los sindicatos contribuyen también al proceso de desarrollo profesional de los docentes. Ellos tienen un margen de autonomía, pero deben tomar en cuenta, de manera particular, la lógica burocrática (marco legal) para concretizar sus acciones. De esta manera, la institución educativa garantiza al máximo que las intervenciones de los sindicatos sean, realmente, para beneficio de los docentes.

\section{Implicación de la cohabitación en el funcionamiento de los distintos niveles institucionales}

La instalación del SINDEPRO implica un ajuste en el funcionamiento de los niveles institucionales (central, regional y local). Es importante señalar que las funciones de los actores educativos, que son implicados en la reestructuración de la dinámica del desarrollo profesional, son prescritas en el Decreto 576. Sin embargo, dada la visión de descentralización, los actores pueden hacer uso de su autonomía. 
En efecto, la cohabitación de las lógicas burocrática y profesional es de gran utilidad en la concretización de las acciones de los actores de los niveles institucionales, puesto que pueden poner en práctica un funcionamiento con base en los principios de centralizacióndescentralización y de control-autonomía. De esta manera, a nivel central, los actores optan por los procedimientos aún centralizados, para hacer valer los deberes de los actores educativos, en el marco de la reestructuración de la dinámica del desarrollo profesional. Sin embargo, ellos apoyan la visión de descentralización del SINDEPRO. Este nivel otorga el poder a los actores de los niveles regional y local para que actúen en base a su margen de autonomía.

De esta forma, el nivel regional tiene un rol estratégico en la instalación del SINDEPRO, dado que dos de sus más importantes componentes (subsistema y el coordinador regional) se encuentran en este nivel. En efecto, en el nivel regional, la cohabitación de las lógicas burocrática y profesional es indispensable para hacer el vínculo entre lo prescrito (nivel central) y la autonomía (nivel local). En términos prácticos, estos componentes legales sostienen la trayectoria profesional de los docentes, reconociendo al mismo tiempo su autonomía. Sin embargo, si tenemos en cuenta los discursos de los actores de los distintos niveles, podemos remarcar que estos procedimientos son más efectivos cuando los docentes son receptivos a la dinámica del desarrollo profesional; es decir, cuando demuestran un grado de "profesionalismo", como es el caso de los docentes que forman parte de este estudio. En el caso contrario, se requiere de estrategias orientadas hacia al aspecto motivacional, con el fin de estimular a los docentes a participar en la dinámica del desarrollo profesional, de manera activa.

Es a nivel local que podemos constatar, aún más, los beneficios de la reestructuración de la dinámica del desarrollo profesional (SINDEPRO) basada en la visión de descentralización. En efecto, a este nivel, la cohabitación de las lógicas tiene lugar, ya que los actores poseen la libertad y por ende el derecho de tomar decisiones, combinándolas al mismo tiempo con la responsabilidad y el deber de concretarlas. Por otra parte, si hacemos referencia a los actores entrevistados en el nivel local, podemos considerar que con esta conjugación de procedimientos el docente podría convertirse en "administrador" de su trayectoria profesional. Pero, hacemos la salvedad, que estos procedimientos están vinculados a la gestión practicada en el centro educativo, a las oportunidades de formación de los docentes, a las condiciones organizacionales, a la motivación, etc. En efecto, estos son algunos aspectos y condiciones que se requieren para sostener y estimular al personal docente, para que sean autores y actores en el ejercicio de su profesión.

En suma, destacamos que en el contexto educativo de Panamá la fórmula "tensióncohabitación" de las dos lógicas (burocrática y profesional) permite de establecer un equilibrio en el funcionamiento de la institución, sobre todo, al momento de los cambios institucionales, como es el caso de la reestructuración de la dinámica del desarrollo profesional de los docentes.

Es necesario resaltar que esta fórmula de funcionamiento es probablemente más apropiada para los sistemas educativos que tienen una "gestión compartida", es decir que la jerarquía concede un grado de poder a los actores de terreno para actuar según sus necesidades particulares, tal como es el caso en el sistema educativo panameño. Aunque la consideración siguiente requiere un mínimo de prudencia, nos atrevemos a manifestar que esta fórmula 
para ser "eficaz" necesita, entre otras condiciones, un grado de profesionalismo de los actores educativos, para que puedan administrar de manera "conveniente" los procedimientos en el contexto de trabajo, combinando el control legal y la autonomía.

\section{Tendencia funcional y comunicacional en el marco de la operacionalización del desarrollo profesional}

Con base en los discursos de los actores entrevistados, podemos resaltar que la importancia otorgada a las lógicas difiere según el nivel institucional (central, regional y local). Esto constituye un factor que convierte la cohabitación en una condición funcional, por lo tanto, necesaria en la operacionalización de la dinámica del desarrollo profesional de los docentes. Pero esta "cohabitación funcional" se conjuga con una "comunicación institucional" concorde a la lógica predominante en el nivel respectivo (central, regional, local). Esta tendencia funcional-comunicacional da coherencia a las acciones de los actores de los distintos niveles en el marco de la operacionalización de la dinámica del desarrollo profesional.

Tal como se evidencia en los resultados obtenidos, en la implantación de la Modernización de la educación panameña, la institución educativa hace uso de la comunicación vertical y adopta progresivamente la comunicación horizontal. No obstante, hacemos la salvedad que en la institución educativa panameña, durante varias épocas, los actores educativos estaban habituados a la utilización de la lógica burocrática y por ende a una comunicación vertical. Esta manera de funcionar es aún, probablemente, adoptada por algunos actores, en situaciones donde es necesario utilizar la lógica profesional y la comunicación horizontal. Si este es el caso, esta manera de funcionar podría generar "discrepancias" en el marco de la reestructuración de la dinámica del desarrollo profesional (Decreto 576, SINDEPRO), ya que esta no elimina la comunicación vertical; sin embargo, en su visión de descentralización, la misma sostiene más bien la comunicación horizontal. Esto es un indicio de que la "fase de transición" es importante en los cambios, para que los actores tengan la posibilidad de apropiarse de nuevos contenidos, así como de la nueva manera de funcionar, que los mismos conllevan.

\section{Proporción de la cohabitación de las lógicas en los distintos niveles}

A través de los discursos de actores de los distintos niveles (central, regional y local), se pudo remarcar la implicación de los mismos, en la operacionalización del desarrollo profesional. De igual manera, se resalta el carácter "utilitario" que estos actores otorgan a la cohabitación de las lógicas organizacionales, según las funciones que ellos ejercen.

En ese sentido, considerando una visión funcional, el nivel central tiene un "rol de controlador-coordinador", ya que es el garante de las finalidades educativas. En este nivel, se hace uso de la lógica burocrática en la gestión del desarrollo profesional, lo que le permite tener un determinado control sobre las acciones de los actores de los otros niveles. Sin embargo, algunos actores del nivel regional y especialmente del nivel local cuestionan este procedimiento por su carácter centralizado. No obstante, es necesario señalar, que en 
este caso, el control es de carácter legal, porque está contemplado en la ley 47, que rige el funcionamiento de la institución educativa.

A través de este procedimiento centralizado, la jerarquía central sostiene lo que hemos denominado "el efecto secuencial de los documentos legales" (concretización de leyes, decretos, resueltos, políticas, etc., de manera relacionada). Estos documentos legales contienen, de manera explícita o implícita, las solicitudes y los resultados esperados por la institución. Por ello, para cumplir con las exigencias de estas disposiciones legales, el nivel central sugiere a los actores participar en la dinámica del desarrollo profesional. En efecto, según los actores educativos del nivel central, a través del desarrollo profesional se puede ampliar y obtener competencias que son necesarias para dar respuestas a las demandas institucionales.

Por otra parte, a través de los informes escritos del Ministerio de Educación, se puede recalcar que la jerarquía central atribuye un "carácter utilitario" muy marcado a la lógica burocrática. Esta manera de funcionar es practicada por la mayoría de los actores del nivel central, puesto que la misma es considerada necesaria para operacionalizar la dinámica del desarrollo profesional de los docentes; teniendo como referencia el marco legal. Es, por lo tanto, indispensable destacar que el nivel central depende de los otros niveles (regional y local) para concretar sus acciones de desarrollo profesional.

Sin embargo, el nivel central no es estrictamente burocrático, puesto que este también hace uso de los principios de la lógica profesional. Es importante señalar que la cohabitación de las lógicas evita de caracterizar el nivel central como "autocrático". De este modo, este nivel promueve la autonomía de los actores, por una parte, para que actúen de manera más adaptada a sus necesidades de desarrollo y, por otra parte, para disminuir los efectos de la centralización. Es evidente que la diferencia de la proporción de la cohabitación de las lógicas se refleja en el hecho de que la jerarquía central utiliza, más que nada la comunicación vertical, con el fin de coordinar, de manera formal, las acciones de desarrollo con los otros niveles (regional y local).

En respuesta a esta línea de funcionamiento, destacamos que el nivel regional adopta en proporción igual la cohabitación de las dos lógicas organizacionales. Este nivel, al ejercer su "rol de intermediario", utiliza, por una parte, la lógica burocrática y una comunicación vertical, para responder a las solicitudes y los procedimientos (administrativos y organizacionales) de la jerarquía central, del cual es relativamente dependiente. Por otra parte, el nivel regional practica la lógica profesional y la comunicación horizontal, con el fin de permanecer a la escucha del nivel local. Además, este nivel motiva a los actores del nivel local a hacer uso de su autonomía, tomando en cuenta el marco legal. No obstante, esta manera de funcionar exige un cambio de actitudes, de los actores del nivel regional, dado que por muchas épocas ellos ejercieron su "rol de intermediario", de acuerdo con la centralización y el control.

No obstante, la tendencia funcional-comunicacional a doble sentido no se concretiza de manera fácil ni simple a nivel regional. En efecto, como lo hemos visto, este nivel debe mantener una actitud en el sentido de la centralización-control y simultáneamente en el sentido de la descentralización-autonomía. Así, el nivel regional para ejercer su rol se ha apropiado de un mecanismo operativo de articulación, a través de una comunicación continua 
con el nivel central y el nivel local. Esto significa que para que el nivel regional pueda ejercer su rol, depende de la existencia del nivel central y el nivel local.

En esta línea de acción, el nivel local denota una diferencia de proporción en la cohabitación de las lógicas, pero a lo opuesto del nivel central. Concretamente, este nivel, para ejercer su "rol de operador", utiliza la lógica burocrática, para mantener un "hilo conductor", en coherencia con los otros niveles. Sin embargo, la lógica profesional se practica considerablemente, con el fin de hacer funcional la operacionalización del desarrollo profesional. Por ello, este nivel emplea la comunicación horizontal, permitiendo así una mayor participación y la movilidad de las competencias entre los docentes.

De igual manera, podemos resaltar que la mayor parte de actores (directores, subdirectores y coordinadores de grado) de las escuelas entrevistadas ponen en práctica el intercambio, la interacción, entre otros, con base en los procedimientos que responden a la descentralización y a la autonomía, lo que favorece una gestión compartida del desarrollo profesional. No obstante, esta manera de proceder implica la voluntad profesional de los directores, la conducta profesional de los docentes, la coordinación y el apoyo permanente del nivel regional, así como la aprobación del nivel central.

Además, es notable la proximidad del nivel local con el nivel regional. Esta proximidad permite la coordinación de acciones y procedimientos de desarrollo profesional. Del mismo modo, los actores del nivel local deben tomar en cuenta los procedimientos centralizados a nivel central, puesto que los mismos son obligatorios.

En suma, con base en estas constataciones, podemos manifestar que la tendencia funcional (proporción de la utilización de la cohabitación de las lógicas) y comunicacional (vertical, horizontal) adoptada en un nivel en particular tiene influencia sobre los otros dos.

Es importante recalcar que la comunicación horizontal es "más efectiva" cuando en la institución existe la "transmisión de información", a través de la coordinación formal y a veces informal. Esta última es posible, ya que la institución permite el ajuste mutuo (Mintzberg, 1982) ${ }^{V I I}$ cuando los procedimientos burocráticos no son necesarios. La utilidad de los dos tipos de comunicación favorece una mayor movilidad de competencias en la gestión de la operacionalización del desarrollo profesional.

Asimismo, se revela que es necesario que los actores de todos los niveles adquieran y desarrollen competencias particulares a su rol, por la puesta en práctica de manera "adecuada" de la tendencia funcional-comunicacional.

\section{Conclusión}

La conclusión se presenta a partir de un modelo comprensivo. El modelo expone diferentes aspectos del funcionamiento de los niveles institucionales (central, regional y local) del sistema educativo panameño. Estos aspectos se consideran en relación con la operacionalización del desarrollo profesional de los docentes, la cual se concretiza entre las lógicas burocrática y profesional. 


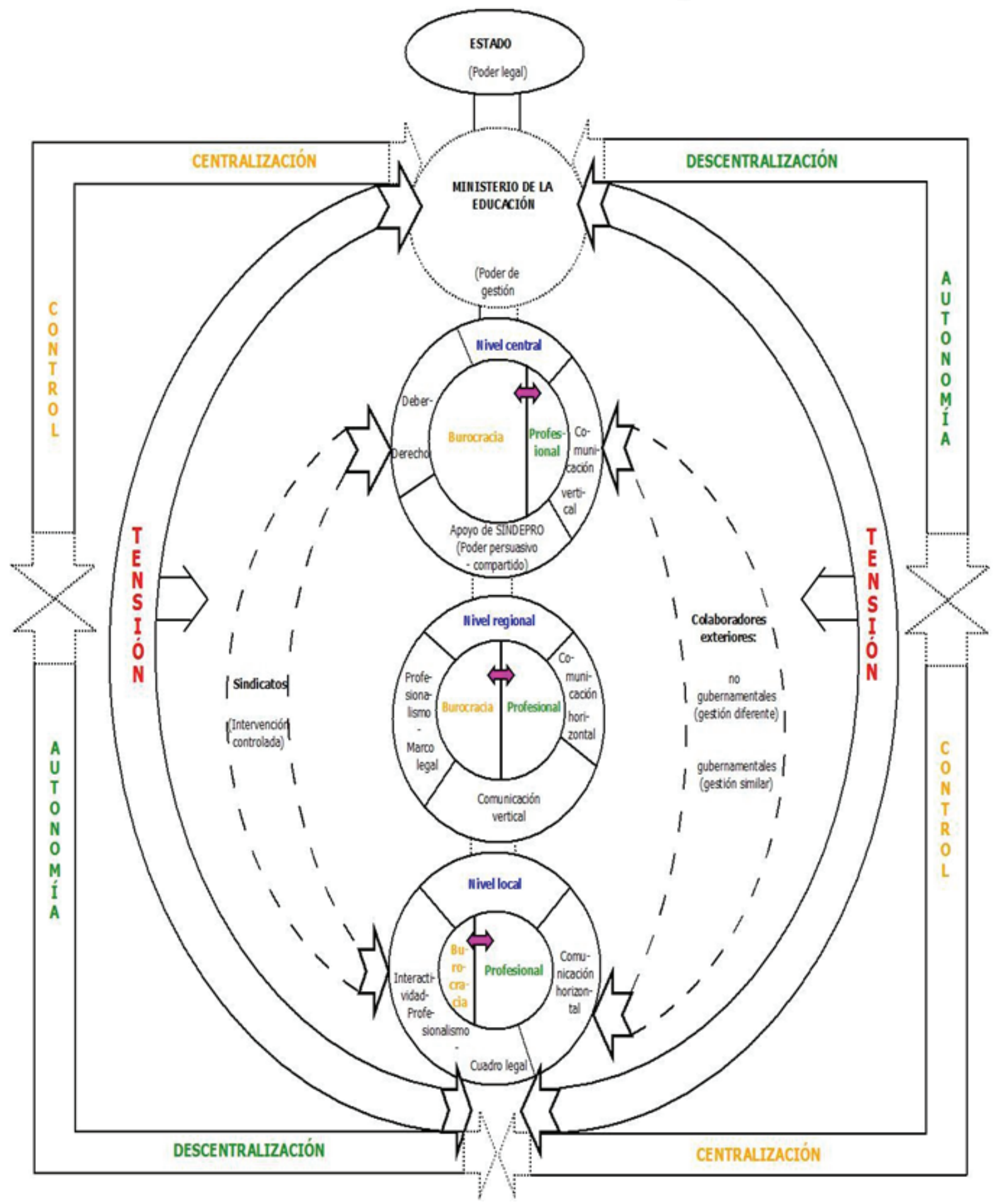

Figura 1. Modelo comprensivo elaborado por Mitzila Matínez León 
El funcionamiento burocrático-profesional del sistema educativo en Panamá implica al origen dos poderes. El primero es el poder legal del Estado, que influye sobre el funcionamiento educativo de manera indirecta, a través de sus solicitudes y expectativas. El segundo es el poder de gestión del Ministerio de Educación, que influye directamente sobre el funcionamiento educativo. Estos poderes determinan el tipo de dinámica de desarrollo profesional de los docentes.

Para los docentes, la burocracia en la institución implica la formalización, la centralización, el control, entre otros. Al contrario, el funcionamiento profesional implica la descentralización, la autonomía, etc. Estos aspectos pueden hacer surgir una tensión, ya que a primera vista parecen antagónicos. Sin embargo, los mismos se utilizan de manera simultánea, a través de la cohabitación entre la lógica burocrática y la lógica profesional.

La cohabitación se concreta de acuerdo a la "utilidad funcional", que es considerada por los actores de los distintos niveles institucionales (central, regional y local). Por ello, la proporción de la cohabitación de las lógicas burocrática y profesional es diferente entre niveles, así como el tipo de comunicación institucional utilizado (vertical u horizontal). Esta diferencia entre los niveles resulta necesaria, precisamente, para mantener un "equilibrio" en el funcionamiento de la institución, de manera que favorezca la operacionalización de la dinámica del desarrollo profesional.

Asimismo, la cohabitación se establece, más fácilmente, cuando los actores educativos comprenden la funcionalidad de las lógicas burocrática y profesional. Por otra parte, esta cohabitación favorece la relación entre actores de los distintos niveles (central, regional y local), ya que a través del marco legal, cada actor sitúa sus funciones, sus deberes, su margen de autonomía, etc., frente a los otros actores.

En este contexto, el SINDEPRO (sistema integral de desarrollo profesional-Decreto 576), basándose en el marco legal (poder persuasivo), sostiene la descentralización (poder compartido) y constituye un apoyo para que los docentes sean los autores y actores de su propio proceso de profesionalización. Tomando en cuenta esta finalidad, los colaboradores exteriores contribuyen a la concretización de la visión de descentralización. Así, las oportunidades de desarrollo de los colaboradores exteriores gubernamental (gestión similar a la institución educativa) y no gubernamental (gestión diferente a la institución educativa) son ineludibles, en la operacionalización del desarrollo profesional. Al contrario, los sindicatos contribuyen al desarrollo profesional de los docentes de manera casi "pasiva", puesto que los mismos son, considerablemente, controlados.

Finalmente, podemos concluir que el funcionamiento burocrático y profesional de la institución educativa, a través de los niveles central, regional y local, es favorable a la operacionalización del desarrollo profesional de los docentes en Panamá. En efecto, la lógica burocrática, que implica la centralización y el control, actúa como un "hilo conductor" para encuadrar de manera formal las acciones de los actores. Igualmente, la lógica profesional, que implica la descentralización y la autonomía, toma en cuenta el profesionalismo, dando a los actores el poder de actuar y de reaccionar, a través de procedimientos, a veces, informales. 


\section{Notas}

I El término "operacionalización" es utilizado en nuestro estudio para hacer referencia a las acciones puestas en práctica, enfocando el desarrollo profesional.

II El término "lógica" es utilizado en el sentido del razonamiento, del método, etc., que enmarca las acciones.

III Ministerio de Educación. Estrategia decenal de modernización escolar. Panamá, 1997.

IV Se recurre al término "organizacional" como adjetivo calificativo de cualquier tipo de elemento o situación relacionada con las organizaciones de diverso tipo.

v El término "estandarización" proviene del término "estándar", el cual se refiere a un modo o método establecido, aceptado y normalmente seguido para realizar determinado tipo de actividad o funciones.

v El poder persuasivo (Galbraith, 1985): modificación del pensamiento en base a un marco legal.

VII El ajuste mutuo es uno de los mecanismos de coordinación (Mintzberg, 1982) que permite la coordinación del trabajo por simple comunicación informal.

\section{Referencias bibliográficas}

Barbier, J.M., Chaix, M. L., y Demailly, L. (1994). Éditorial. Recherche et formation, 17, 5-8.

Barbier, J. M., Berton, F., Boru, J., Charlon, E., Courtois, E., Geslin, M.P., ... Richard, R. (1996). Situations de travail et formation. Paris: L'Harmattan.

Bardin, L. (2001). L'analyse de contenu (10ª ed.). Paris: PUF.

Bonami, M. y Garant, M. (1996). Système scolaire et pilotage des innovations. Emergence et implantation du changement. Paris, Bruxelles: De Boeck \& Larcier.

Bosman, CH. (2000). Quel avenir pour les compétences? Bruxelles: Editions De Boeck Université.

Boucher, L.P. y L’Hostie, M. (1997). Le développement professionnel continu en éducation. Nouvelles pratiques. Québec: Presses de l'Université du Québec.

Brunet, J.P. y Brunet, L. (2001). Les paradoxes en éducation. Québec: Les Editions Logiques.

Donnay, J. y Charlier, E. (2000). Identité et développement. En A. Abou y M. J. Guiletti, Enseignants d'Europe et d'Amérique: Question d'identité et de formation. Paris: I.N.R.P.

Donnay, J. y Charlier, E. (2006). Apprendre par l'analyse de pratiques. Initiation au compagnonnage réflexif. Namur: Presses universitaire de Namur.

Galbraith, J. K. (1985). Anatomie du pouvoir. Paris: Le Seuil.

Gather-Thurler, M. (2000). Innover au cour de l'établissement scolaire. Paris: ESF. 
Gustin, A. (2002). Management des établissements scolaire. De l'évaluation institutionnelle à la gestion stratégique. Bruxelles: De Boeck \& Lancier s.a.

Hatch, M.J. (2001). Théorie des organisations: de lintérêt de perspectives multiples. Paris: De Boeck Université.

Holborn, P., Wideen, M. y Andrews, I. (Dir.) (1993). Devenir enseignant. T II. D’une expérience de survie à la maîtrise d'une pratique professionnelle. Montréal: Les Éditions Logiques.

Huberman, M. (1991). Analyse des données qualitatives. Recueil de nouvelles méthodes. Bruxelles: De Boeck- Wesmael.

Chavy, J. y Dampierre, E. (1971). Economie et Société. Paris: Ed. Pocket (Publication originale, posthume, 1921).

Lieberman, A. y Miller, L. (1990). Teacher development in professional practice. Teachers College Record, 92(1), 105-121.

Mintzberg, H. (1982). Structures \& dynamiques des organisations. Paris: les éditions d'organisation.

Mintzberg, H. (1986). Le pouvoir dans les organisations. Paris: les éditions d'organisation.

Mintzberg, H. (1990). Le management. Voyage au centre des organisations. Paris: les éditions d'organisation.

Mintzberg, H. (1996). Structures \& dynamiques des organisations ( $\left.{ }^{a} E d.\right)$. Paris: les éditions d'organisation.

Paille, P. y Mucchielli, A. (2003). L'analyse qualitative, en sciences humaines et sociales. Paris: Ed. Armand Colin.

Perrenoud, P. (1994). La formation des enseignants, entre théorie et pratique. Paris: L'Harmattan.

Vonk, J. C. (1988). L'évolution professionnelle des enseignants débutants et ses répercussions sur la formation initiale et continue. Recherche et formation, 3(3), 47-60. 


\section{Anexo}

Matriz concerniente a las guías de las entrevistas de los diferentes niveles institucionales (central, regional y local)

\section{Nivel central (actores de la jerarquía central y colaboradores exteriores) y nivel regional (actores de la jerarquía regional y representantes de sindicatos) \\ Objetivo de la entrevista}

Para comprender la dinámica de desarrollo profesional del personal docente, se busca obtener información sobre el funcionamiento de la institución educativa, así como de las representaciones de desarrollo profesional de los actores de estos niveles (central y regional). De igual manera, se busca conocer los proyectos, acciones, estrategias y las relaciones entre actores, que son puestas en práctica, para apoyar y mantener el desarrollo profesional.

\begin{tabular}{|c|c|}
\hline Preguntas operacionales y de recuadro & Conceptos de referencia \\
\hline \multicolumn{2}{|c|}{$\begin{array}{c}\text { Representación, proceso de elaboración y de sostén de las políticas, los proyectos, las acciones.. } \\
\text { del desarrollo profesional en el marco del funcionamiento de la institución }\end{array}$} \\
\hline $\begin{array}{l}\text { - ¿Qué significa para usted el desarrollo profesional del } \\
\text { personal docente? } \\
\text { - ¿De qué manera la institución apoya a los docentes a nivel } \\
\text { profesional? } \\
\text { - ¿Es este apoyo favorable para los docentes? } \\
\text { - ¿Sobre qué se basa la institución para definir las políticas } \\
\text { y las estrategias de desarrollo profesional de los docentes? } \\
\text { ¿Quién las elabora? } \\
\text { - ¿Existe la concertación con los actores de terreno en la fase } \\
\text { de elaboración de políticas, estrategias, acciones? ¿Toman } \\
\text { ustedes cuenta del contexto de los centros educativos? } \\
\text { - ¿De qué manera el funcionamiento de la institución es } \\
\text { favorable a las políticas, estrategias, acciones...? }\end{array}$ & $\begin{array}{l}\checkmark \text { Funcionamiento institucional } \\
\checkmark \text { Configuraciones estructurales } \\
\checkmark \text { Noción de desarrollo profesional } \\
\checkmark \text { Medidas de sostén del desarrollo } \\
\text { profesional }\end{array}$ \\
\hline
\end{tabular}


Transmisión de los contenidos de la dinámica de desarrollo profesional

- ¿A través de qué proceso son trasmitidas las políticas y estrategias a los establecimientos escolares?

- ¿Cómo reaccionan los docentes frente a estos procedimientos?

- ¿Qué actores en la institución, tienen que ver con el desarrollo profesional de los docentes? ¿Cómo ellos colaboran?

- ¿Qué actores son encargados de transmitir las políticas, las estrategias...a los centros educativos?

- ¿Qué medidas son permitidas por la institución a nivel de la escuela, en relación a la aplicación de las políticas y de las estrategias de desarrollo profesional?

- ¿Tienen los centros educativos un margen de libertad para adaptar los contenidos de la dinámica de desarrollo profesional?

- ¿Cómo la institución maneja los rechazos de las políticas y las estrategias del aspecto profesional? $\checkmark$ Funcionamiento y estructura organizacional

$\checkmark$ Estrategias de influencia (presión y legitimación) modos de organización,

$\checkmark$ Mecanismos de coordinación

\section{Ocasiones de desarrollo profesional en el contexto interno o externo de la institución}

- ¿Qué actividades y oportunidades de desarrollo profesional son ofrecidas a los docentes?

- ¿Qué parámetros son tomados en cuenta para elaborar las actividades y las oportunidades de desarrollo profesional?

- ¿Cómo son organizadas para concretizarlas?

- ¿Las experiencias de los docentes son tomadas en cuentas?

- ¿Cuáles son las actividades profesionales privilegiadas por los docentes?

- ¿Qué otras instituciones o asociados contribuyen al desarrollo profesional de los docentes?

- ¿De qué manera los apoyos de los colaboradores exteriores favorecen el desarrollo profesional de los docentes? $\checkmark$ Concepción del desarrollo profesional $\checkmark$ Paradigmas del desarrollo profesional

$\checkmark$ Detentores internes y externos 


\section{Entrevistas de los colaboradores exteriores}

\section{Objetivo}

Obtener informaciones de la manera cómo los colaboradores exteriores favorecen e intervienen en el desarrollo profesional de los docentes.

Coordinación de la dinámica de desarrollo profesional entre la institución educativa y los colaboradores exteriores.

- ¿Qué procedimientos son realizados para establecer la relación con la institución educativa, con la finalidad de intervenir en el desarrollo profesional de los docentes?

- ¿En qué su representación de la dinámica de desarrollo profesional es parecida o diferente a la de la institución educativa?

\section{Contribución a la dinámica de desarrollo profesional de los docentes}

- ¿Cómo contribuye ustedes en la dinámica de desarrollo?

$\checkmark$ Concepción del desarrollo profesional

- ¿Cuáles son las ocasiones de desarrollo ofrecidas a los docentes?

- ¿Cuáles estrategias aplican ustedes para concretizar las ocasiones de desarrollo profesional?

- ¿Cómo los docentes perciben sus intervenciones?

- ¿Participan los docentes a estas ocasiones de desarrollo profesional?

\section{Entrevista de los representantes de sindicatos de docentes}

\section{Objetivo}

Saber cómo contribuyen o influencian los sindicatos la dinámica de desarrollo profesional de los docentes.

\section{Contribución de desarrollo profesional de los docentes}

- ¿Cómo intervienen ustedes en el desarrollo profesional de los docentes?

- ¿Toman ustedes en cuenta las políticas y estrategias de desarrollo profesional prescritas por la institución?

- ¿Visualizan ustedes políticas, estrategias...Cuáles? $\checkmark$ Funcionamiento y estructura organizacional

$\checkmark$ Relación de poder

$\checkmark$ Desarrollo profesional 


\section{Representación y ocasión de desarrollo profesional}

- ¿Cuál es la significación que usted le da al desarrollo $\checkmark$ Definición de desarrollo profesional profesional?

- ¿Cómo hacen ustedes para transmitir su representación de $\checkmark$ Concepción de desarrollo desarrollo profesional a los docentes? profesional

- ¿Cuáles son las ocasiones de desarrollo profesional ofrecidas a los docentes?

- ¿Cómo los docentes perciben estas oportunidades de desarrollo profesional?

\section{Nivel local (directores de centros educativos)}

\section{Objetivo de la entrevista}

En este nivel se busca obtener informaciones acerca del funcionamiento del centro educativo, así como de las representaciones del desarrollo profesional. Igualmente, se busca comprender la manera cómo los actores del centro educativo obtienen las informaciones y sostienen la dinámica de desarrollo profesional del personal docente.

\begin{tabular}{|c|c|}
\hline Preguntas operacionales y de recuadro & Conceptos de referencias \\
\hline \multicolumn{2}{|c|}{$\begin{array}{c}\text { Representación y procedimientos concernientes a la elaboración y la comunicación de la } \\
\text { dinámica de desarrollo profesional de los docentes }\end{array}$} \\
\hline $\begin{array}{l}\text { - ¿Qué significa para usted el crecimiento } \\
\text { profesional de los docentes? } \\
\text { - ¿Cuál es el procedimiento para la elaboración y } \\
\text { la aplicación de las estrategias que conciernen } \\
\text { el aspecto profesional de los docentes? ¿Es usted } \\
\text { tomado en cuenta? } \\
\text { - ¿Cómo colaboran los niveles central y regional } \\
\text { en la aplicación de de estas estrategias? } \\
\text { - ¿Cómo son ustedes informados de los conteni- } \\
\text { dos de las nuevas políticas, estrategias, acciones } \\
\text { concernientes al desarrollo profesional? }\end{array}$ & $\begin{array}{l}\checkmark \text { Noción de desarrollo profesional } \\
\checkmark \text { Concepción tradicional y nuevo paradigma de } \\
\text { desarrollo profesional } \\
\checkmark \text { Funcionamiento y estructura organizacional }\end{array}$ \\
\hline \multicolumn{2}{|c|}{$\begin{array}{c}\text { Condiciones de sostén puestas en práctica en la dinámica de desarrollo profesional en el } \\
\text { marco del funcionamiento y la organización del centro educativo. }\end{array}$} \\
\hline $\begin{array}{l}\text { ¿Qué medidas son tomadas en los niveles central } \\
\text { y regional en la escuela para que los docentes } \\
\text { participen en las actividades profesionales? } \\
\text { ¿Cómo reaccionan los docentes frente a estas } \\
\text { medidas? }\end{array}$ & $\checkmark$ Estrategias de presión y de legitimación. \\
\hline
\end{tabular}


- ¿Qué acciones son puesta en práctica a nivel institucional y de la escuela para promover la aplicación de las políticas y las estrategias del aspecto profesional de los docentes?

- ¿Los apoyos de la institución son favorables para la dinámica de desarrollo profesional?

- ¿Qué actividades profesionales son privilegiadas según el funcionamiento de la escuela?

$\otimes$ Esfera de desarrollo profesional, formación continua

- ¿Existen espacios de concertación de las actividades del aspecto profesional?

\section{Margen de autonomía para la concretización de la dinámica de desarrollo profesional}

- ¿Tienen ustedes en la escuela la libertad $\checkmark$ Autonomía, cultura de adaptar los mandatos institucionales concernientes al desarrollo profesional?

$\checkmark$ Lógicas organizacionales

- ¿Qué medidas son puesta en práctica para adaptar los mandatos institucionales concernientes a las acciones profesionales de los docentes al funcionamiento de la escuela?

- ¿Qué son aquellas permitidas por la institución?

- ¿Cómo los docentes adaptan los intereses a las actividades y las acciones en relación al aspecto profesional?

$\checkmark$ Mecanismos de regulación

$\checkmark$ Lógicas organizacionales

- ¿Qué procedimientos son adoptados por los docentes para aplicar e implicarse en las actividades en relación al aspecto profesional?

\section{Ocasiones de desarrollo profesional al interior o al exterior del centro educativo}

- ¿En qué actividades, acciones...concernientes al $\checkmark \checkmark$ Esfera de desarrollo profesional desarrollo profesional participan los docentes?

- ¿Dónde se organizan las actividades, acciones y por quién?

- ¿Qué parámetros toman en cuenta los diferentes niveles central, regional y local para organizar las acciones de desarrollo?

- ¿Qué otras personas u organizaciones exteriores están asociadas a la escuela?

- ¿Cómo estas personas u organizaciones entran en relación con las actividades y las acciones en relación al aspecto profesional de los docentes?

- ¿Estas personas u organizaciones influencian la representación que los docentes tienen de su profesión? ¿De qué manera?

$\checkmark$ Cultura del centro educativo 


\section{Nivel local (docentes coordinadores de grado)}

\section{Objetivo de la entrevista}

A nivel local, se busca comprender la dinámica de desarrollo profesional. Además, se busca conocer la representación de los docentes acerca de su desarrollo profesional.

Preguntas operacionales y de recuadro

Conceptos de referencias

Representación de la dinámica de desarrollo profesional y procedimientos puestos en práctica para concretizarla de acuerdo al funcionamiento del los niveles central, regional y local.

- ¿Qué significa para ustedes el crecimiento profesional dentro de su profesión?

- ¿Cómo pueden ustedes responder a sus necesidades profesionales?

- ¿Qué piensa usted de las actividades y acciones profesionales visualizadas por la institución?

- ¿Estas actividades toman en cuenta los parámetros en relación al contexto educativo?

- ¿Tienen ustedes la libertad para adaptar la aplicación de los mandatos institucionales del aspecto profesional dentro de la escuela?

- ¿Cuáles son las acciones, medios, condiciones...que son puestas en práctica según el funcionamiento de la escuela?

- ¿Son ustedes concertados para elaborar las actividades, acciones de desarrollo profesional?

Organización de los docentes por la concretización de estrategias y proyectos de desarrollo profesional, tomando en cuenta el margen de autonomia.

- ¿Cómo ustedes se organizan para poner en práctica las actividades y las acciones profesionales, así que los nuevos mandatos?

- ¿Qué medidas toman ustedes como grupo?

- ¿Pueden ustedes adaptar las actividades y las acciones profesionales prescritas a sus necesidades $\checkmark$ Noción de desarrollo profesional

$\checkmark$ Funcionamiento institucional 
Percepción de las ocasiones de desarrollo profesional al interior y al exterior del centro educativo

- ¿En qué actividades o acciones profesionales participan ustedes? ¿Quién organiza las mismas

- ¿Qué piensa usted de las actividades, acciones de desarrollo profesional organizadas al interior y al exterior del centro educativo?

- ¿En estas actividades son tomadas en cuenta sus experiencias?

\section{Influencia de redes sociales en el desarrollo profesional}

- ¿Forma usted parte de grupos profesionales?

- ¿Influencian los grupos profesionales su manera de actuar en la escuela?

- ¿Cómo estos grupos contribuyen a que ustedes puedan dar respuesta a sus necesidades profesionales? $\checkmark$ Esfera de desarrollo profesional

$\checkmark$ Elementos y paradigmas de desarrollo profesional 